\title{
Mental work load analysis melalui national aeronautics and space administration (NASA)-task load index (TLX)
}

\author{
Ari Teguh Septiansyah ${ }^{1{ }^{*}}$, Risma Fitriani ${ }^{2)}$, Billy Nugraha ${ }^{3)}$ \\ ${ }^{1,2}$ Universitas Singaperbangsa Karawang, Jl. HS. Ronggo Waluyo, Puseurjaya, Kecamatan Telukjambe Timur, \\ Kabupaten Karawang - 41361, Indonesia. \\ ${ }^{3}$ Akademi Komunitas Presiden, Jababeka Education Park, Jl. Ki Hajar Dewantara Kota Jababeka, Cikarang \\ Utara, Kota Bekasi - 17550, Indonesia.
}

ariteguh179@gmail.com *; risma.fitriani@ft.unsika.ac.id ; billynugraha982@gmail.com

\begin{abstract}
ABSTRAK
Salah satu industri manufaktur yang bergerak pada bidang stamping, assy welding, jig \& dies, automotive \& non automotive adalah PT. Putra Kemuning. Dilakukannya penelitian ini pada karyawan departemen produksi di posisi quality assurance, die maintenance \& produksi, pre delivery \& finished goods, stamping \& welding, setiap mesin hanya dikelola oleh satu karyawan pada setiap stasiunnya. Melalui hasil pengamatan serta kuesioner yang dilakukan pada PT. Putra Kemuning di departemen produksi, setiap karyawannya dituntut untuk mempunyai ketelitian, mental, fisik, dan energi yang besar. Karyawan memiliki waktu kerja 8 jam/hari dengan waktu istirahat $1 \mathrm{jam} / \mathrm{hari}$, terkecuali di hari jumát. Penelitian bertujuan untuk menganalisis tingkatkan mental work load, didapatkan karyawan yang sedang bekerja melalui National Aeronautics and Space Administration (NASA) - Task Load Index (TLX) Method. Pengukuran melalui enam variabel yang berdasarkan dari metode tersebut. Didapatkan hasilnya: 4 operator $(44,44 \%)$ mempunyai mental work load yang tinggi, 5 operator $(55,56 \%)$ mempunyai beban kerja mental yang sedang, serta 0 operator yang mempunyai mental work load rendah. Dari penelitian guna mengurangi tingginya mental work load dengan ditambahkannya karyawan pada posisi welding serta stamping, maka mempunyai hasil yang signifikan.
\end{abstract}

Kata kunci: Pengukuran, Industry Manufacture, Mental Work Load, NASA, TLX Method.

\section{ABSTRACT}

One of the manufacturing industries engaged in stamping, assy welding, jig \& dies, automotive \& non automotive is PT. Kemuning's son. This study was conducted on employees of the production department in the position of quality assurance, die maintenance \& production, pre delivery \& finished goods, stamping \& welding, each machine is only managed by one employee at each station. Through observations and questionnaires conducted at PT. Kemuning's son in the production department, every employee is required to have great rigor, mental, physical, and energy. Employees have a working time of 8 hours / day with a break of 1 hour / day, except on Fridays. The research aims to analyze the improved mental work load, obtained by employees who are working through the National Aeronautics and Space Administration (NASA) - Task Load Index (TLX) Method. Measurement through six variables based on the method. Results: 4 operators (44.44\%) have a high mental work load, 5 operators (55.56\%) have a moderate mental workload, and 0 operators who have a low mental work load. From research to reduce the high mental work load with the addition of employees in welding and stamping positions, it has significant results.

Keywords: Measurement, Industry Manufacture, Mental Work Load, NASA, TLX Method.

diunggah: November 2021, direvisi: Desember 2021, diterima: Desember 2021, dipublikasi: Desember 2021

Copyright (c) 2021 Ari Teguh Septiansyah, Risma Fitriani, Billy Nugraha

This is an open access article under the CC-BY license 


\section{PENDAHULUAN}

Dalam era globalisasi saat ini, khususnya di sektor industri setiap perusahaan di tuntut untuk memberikan produksi barang atau jasa, yang nantinya dapat digunakan oleh para konsumen dengan nyaman dan aman. Dalam memberikan hasil produk terbaik, dibutuhkan sumber daya manusia atau biasa disebut dengan pekerja (Nugraha, 2021). Posisi pekerja pada perusahaan akan menentukan sebabnya, jika tidak adanya pekerja dan fasilitas maka tidak akan berfungsi (Risma, 2010; Utami, 2012). Maka dari itu sangat diperlukan untuk diketahuinya mental work load karyawan. Mental work load suatu perbaikan manusia dengan batas beban atensi selagi melaksanakan peran pekerjaannya dengan maksimal yakni antara kapasitas, motivasi dan tuntutan kerja (Adiyanto \& Herwanto, 2021; Afma, 2016; Amri \& Herizal, 2017). Potensi manusia salah satunya merupakan modal perusahaan yang harus dikendalikan dengan sangat baik, mengingat akan berakibat pada kemampuan yang dilakukan bagi perusahaan. Manajemen yang optimal itu berisi dengan yang dibuat oleh karyawan mampu mencukupi apa yang diinginkan bagi perusahaan tersebut (Gautama, et al., 2020; Bandono, et al., 2020). Dalam melaksanakan aktivitas sehari-hari manusia memerlukan fisik dan pikiran. Tingkat kesulitan pekerjaan yang dijalankan berpengaruh pada tingginya tenaga fisik dan pikiran. Perbedaan work load diakibatkan dari tingkat kesulitan yang berbeda-beda di setiap pekerjaannya (Kakerisa, et al., 2019; Bastari, et al., 2021).

PT. Putra Kemuning yaitu salah satu perusahaan Indonesia dalam bidang manufacturing automotive \& non automotive. Terdapat beberapa departemen yang saling terhubung dan teratur di PT. Putra Kemuning. Hal ini untuk mewujudkan tujuan dari perusahaan. Dalam melaksanakan suatu rantai produksi, PT. Putra Kemuning perlu memiliki pekerja atau sumber daya manusia yang baik dan benar serta tiap-tiap pekerja mempunyai tugas berbeda-beda serta tiap-tiap pekerjaan dapat menimbulkan work load tersendiri agar produknya yang dihasilkan berkualitas dan dapat terus diproduksi secara berkelanjutan atau tidak berhenti produksi. Maka dari itu dirasa harus untuk menganalisis tentang beban kerja mental dengan baik sesuai visi serta misi pada PT. Putra Kemuning (Suparti, et al., 2018; Budiman, 2013). Dalam hal ini PT. Putra Kemuning perlu mengetahui berapa tinggi mental work load yang didapatkan karyawan pada departemen produksi. Agar dapat mengetahui tingginya mental work load karyawan di departemen produksi. Pengukuran dilaksanakan melalui metode NASA-TLX dengan kuisioner. Hal ini bertujuan agar mendapatkan data relevan dan mengetahui kegiatan kerja serta waktu yang diperlukan karyawan departemen produksi PT. Putra Kemuning (Dewi, 2020; Diniaty, 2016; Diniaty, 2016; Amri \& Herizal, 2017; Afma, 2016).

\section{METODE \\ Metode NASA-TLX}

Metode tersebut bertujuan menganalisis mental work load. Akibat timbulnya keperluan pengukuran yang subjektif terdiri pada 9 variabel (kesusahan pekerjaan, beban waktu, macam kegiatan, kegiatan fisik, kegiatan mental, kinerja, kegagalan, banyak pikiran serta keletihan) yang membuat metode ini dikembangkan. Dari 9 variabel dipermudah menjadi 6 variabel yakni: kebutuhan mental-mental demand (MD), kebutuhan fisik-physical Demand (PD), kebutuhan waktu-temporal demand (TD), kinerja-performance (P), usaha-effort (E) serta tingkat frustasi-frustration level (FL) (Hart, 1988). 6 variabel akan menilai mental work load National Aeronautics and Space Administration (NASA) - Task Load Index (TLX) Method. Guna memperoleh peringkat pada variabel ini dibutuhkan 20 langkah. Diperoleh skor mulai dari 0 sampai dengan 100 di setiap skala. Untuk menggabungkan 6 variabel individu menjadi skor akhir itu merupakan tata cara dalam pembobotan; membutuhkan tata cara perbandingan berupa bagian dua dimensi sebelum penilaian mental work load. Membutuhkan karyawan 
dalam menentukan dimensi yang sangat signifikan serta beban kerja pada segala bagian ke-6 variabel dalam perbandingan berpasangan. Untuk tugas yang diberikan karyawan merupakan hasil variabel terpilih menjadi bobot yang sangat signifikan dan menjadi variabel. Diperoleh skor work load mulai dari 0 sampai dengan 100 bagi tiap-tiap hasil variabel serta memberikan pengalihan beban serta hasil variabel, menambahkan semua variabel, juga dibagi terhadap 15 (hasil terbanding yang berkaitan) (Rubio, et al., 2004; Fithri \& Anisa, 2017; Gautama, et al., 2020). Pada Tabel 1. yaitu variabel work load hendak dilakukannya pengukuran pada National Aeronautics and Space Administration (NASA) - Task Load Index (TLX) Method.

Tabel 1. Variabel dalam national aeronautics and space administration (NASA) - task
load index (TLX) method

\section{Pembobotan}

Responden dimohon agar memberikan lingkaran pada 1 dari 2 variabel yang dialami sangat berpengaruh yang mengakibatkan mental work load mengenai pekerjaannya. Berdasarkan angket National Aeronautics and Space Administration (NASA) - Task Load Index (TLX) Method yang dibagikan berupa sandingan yang berkaitan tentang 15 sandingan berkaitan. Pada angket didapakan total tally pada tiap-tiap variabel yang dialami lebih terpengaruh. Hal yang menjadikan pembobotan pada tiap-tiap variabel mental work load yaitu total tally (Widananto \& Nugraheni, 2019; Arsi, 2012).

\section{Pemberian rating}

Responden dimohon untuk memberi rating tentang 6 variabel mental work load. Tingkatan yang didapatkan merupakan individual/personal terpengaruh melalui mental work load yang dialami responden dengan rentang 0-100. Dengan memperoleh hasil mental work load National Aeronautics and Space Administration (NASA) - Task Load Index (TLX) Method, pembobotan serta tingkatan dengan tiap-tiap variabel digandakan selanjutnya ditambahkan serta dipecah menjadi 15 (jumlah sandingan berkaitan) (Sari, 2019; Kulak \& Tuzuner, 2020).

\section{Teknik pencarian dan pengumpulan data}

Adapun 3 teknik dala pencarian dan pengumpulan data dilaksanakan (Muslimah \& Hastuti, 2017; Putri, et al., 2018; Putri \& Handayani, 2017):

1. Angket, guna mendapatkan mental work load yang terjadi pada karyawan menggunakan angket NASA-TLX.

2. Wawancara, agar dapat mengetahui identitas pada tiap-tiap karyawan serta mengetahui 
komplain yang dialami pada karyawan departemen produksi pada penelitian ini menggunakan wawancara.

3. Observasi secara langsung, untuk mengetahui aktivitas pekerjaan yang dilakukan oleh karyawan departemen produksi pada penelitian ini menggunakan observasi.

\section{HASIL DAN PEMBAHASAN}

Angket hasil pembobotan

Dilaksanakan pembobotan pada 9 orang karyawan PT. Putra Kemuning bagian departemen produksi dengan melingkari salah satu pada pasangan kategori yang sangat berpengaruh jadi sumber pada mental work load bobot diberikan responden berkisar dari nilai 1-5. Hasil dari tahap pembobotan pada Tabel 2.

Tabel 2. Data kuesioner pembobotan

\begin{tabular}{clccccccc}
\hline \multirow{2}{*}{$\begin{array}{c}\text { Responden } \\
\text { (K: Karyawan) }\end{array}$} & \multicolumn{7}{c}{ Potal } & \multirow{2}{*}{ Total } \\
\cline { 2 - 7 } & \multicolumn{1}{c}{ MD } & PD & TD & P & FL & E & \\
\hline K-1 & Quality Assurance & 2 & 4 & 3 & 5 & 0 & 1 & 15 \\
K-2 & Operator Stamping & 2 & 2 & 1 & 5 & 3 & 2 & 15 \\
K-3 & Operator Stamping & 1 & 4 & 3 & 2 & 3 & 2 & 15 \\
K-4 & Operator Stamping & 1 & 3 & 1 & 4 & 4 & 2 & 15 \\
K-5 & Operator Welding \& Stamping & 2 & 4 & 1 & 3 & 2 & 3 & 15 \\
K-6 & Operator Stamping & 1 & 3 & 1 & 4 & 4 & 2 & 15 \\
K-7 & Die Maintenance \& Produksi & 5 & 2 & 1 & 4 & 1 & 2 & 15 \\
K-8 & Pre Delivery \& Finished & 3 & 1 & 1 & 5 & 2 & 3 & 15 \\
K-9 & Goods & 1 & 4 & 5 & 2 & 3 & 0 & 15 \\
\hline
\end{tabular}

\section{Penentuan tingkatan}

Penentuan tingkatan adalah proses selanjutnya yang telah dilaksanakannya proses pemberian bobot. Ditahap tingkatan diskala 0-100 dibagikan pada tiap-tiap variabel sesuai mengenai kejadian yang dirasakan pada karyawan departemen produksi didapatkan melalui angket yang diisi oleh karyawan yang berkaitan. Karyawan tersebut melingkari tingkatan pada mental work load yang ditanyakan dalam angket. Pada Tabel 3. ini merupakan Hasil dari pemberian tingkatan.

\section{Tabel 3. Data penentuan tingkatan}

\begin{tabular}{clcccccc}
\hline \multirow{2}{*}{$\begin{array}{c}\text { Responden } \\
\text { (K: Karyawan) }\end{array}$} & \multicolumn{9}{c}{ Total } \\
\cline { 3 - 8 } & & MD & PD & TD & P & FL & E \\
\hline K-1 & Quality Assurance & 60 & 90 & 70 & 70 & 70 & 80 \\
K-2 & Operator Stamping & 80 & 90 & 80 & 70 & 80 & 90 \\
K-3 & Operator Stamping & 70 & 80 & 90 & 100 & 90 & 100 \\
K-4 & Operator Stamping & 80 & 80 & 90 & 90 & 100 & 90 \\
K-5 & Operator Welding \& Stamping & 100 & 100 & 100 & 50 & 80 & 70 \\
K-6 & Operator Stamping & 90 & 80 & 80 & 90 & 100 & 90 \\
K-7 & Die Maintenance \& Produksi & 70 & 80 & 70 & 80 & 80 & 70 \\
K-8 & Pre Delivery \& Finished Goods & 90 & 80 & 60 & 80 & 50 & 70 \\
K-9 & Operator Stamping & 60 & 70 & 80 & 90 & 80 & 100 \\
\hline
\end{tabular}

\section{Perhitungan nilai weighted work load (WWL)}

Sesudah melakukan pengumpulan data pada angket, maka selanjutnya yaitu melakukan pengolahan data. Berikut merupakan nilai WWL untuk tiap-tiap karyawan departemen produksi pada Tabel 4. 
Tabel 4. Nilai WWL

\begin{tabular}{|c|c|c|c|c|c|c|c|c|c|}
\hline \multirow{2}{*}{$\begin{array}{c}\text { Responden } \\
\text { (K : Karyawan) }\end{array}$} & \multirow{2}{*}{ Posisi } & \multicolumn{6}{|c|}{ Total } & \multirow{2}{*}{ Total } & \multirow{2}{*}{ Nilai } \\
\hline & & MD & PD & TD & $\mathbf{P}$ & FL & $\mathbf{E}$ & & \\
\hline $\mathrm{K}-1$ & Quality Assurance & 120 & 360 & 210 & 350 & 0 & 80 & 1120 & 74,60 \\
\hline $\mathrm{K}-2$ & Operator Stamping & 160 & 180 & 80 & 350 & 240 & 180 & 1190 & 79,33 \\
\hline $\mathrm{K}-3$ & Operator Stamping & 70 & 320 & 270 & 200 & 270 & 200 & 1330 & 88,67 \\
\hline $\mathrm{K}-4$ & Operator Stamping & 80 & 240 & 90 & 360 & 400 & 180 & 1350 & 90,00 \\
\hline K-5 & $\begin{array}{l}\text { Operator Welding } \\
\text { Stamping }\end{array}$ & 200 & 400 & 100 & 150 & 160 & 210 & 1220 & 81,33 \\
\hline K-6 & Operator Stamping & 90 & 240 & 80 & 360 & 400 & 180 & 1350 & 90,00 \\
\hline $\mathrm{K}-7$ & Die Maintenance \& Produksi & 350 & 160 & 70 & 320 & 80 & 140 & 1120 & 74,67 \\
\hline K-8 & $\begin{array}{l}\text { Pre Delivery \& Finished } \\
\text { Goods }\end{array}$ & 270 & 80 & 60 & 400 & 100 & 210 & 1120 & 74,67 \\
\hline K-9 & Operator Stamping & 60 & 280 & 400 & 180 & 240 & 0 & 1160 & 77,33 \\
\hline
\end{tabular}

\section{Klasifikasi penilaian mental work load}

Hasil dari pengolahan rata-rata WWL dikonversikan kepada 3 kategori sesuai pada Tabel 5., yakni jika rata-rata WWL memperlihatkan nilai $<50$ maka dinyatakan beban kerja mental rendah, jika rata-rata WWL memperlihatkan nilai antara 50 sampai 80 maka dinyatakan beban kerja mental sedang dan jika rata-rata WWL memperlihatkan nilai $\geq 80$ maka dinyatakan beban kerja mental tinggi.

Tabel 5. Kategori penilaian mental work load

\begin{tabular}{ccc}
\hline Responden & Nilai WWL & Kategori \\
\hline K-1 & 74,60 & Sedang \\
K-2 & 79,33 & Sedang \\
K-3 & 88,67 & Tinggi \\
K-4 & 90,00 & Tinggi \\
K-5 & 81,33 & Tinggi \\
K-6 & 90,00 & Tinggi \\
K-7 & 74,67 & Sedang \\
K-8 & 74,67 & Sedang \\
K-9 & 77,33 & Sedang \\
\hline
\end{tabular}

Berdasarkan Tabel 5 di atas, dapat diklasifikasikan mental work load karyawan departemen produksi PT. Putra Kemuning jika diilustrasikan ke dalam Gambar 1. Grafik Mental Work Load berikut ini.

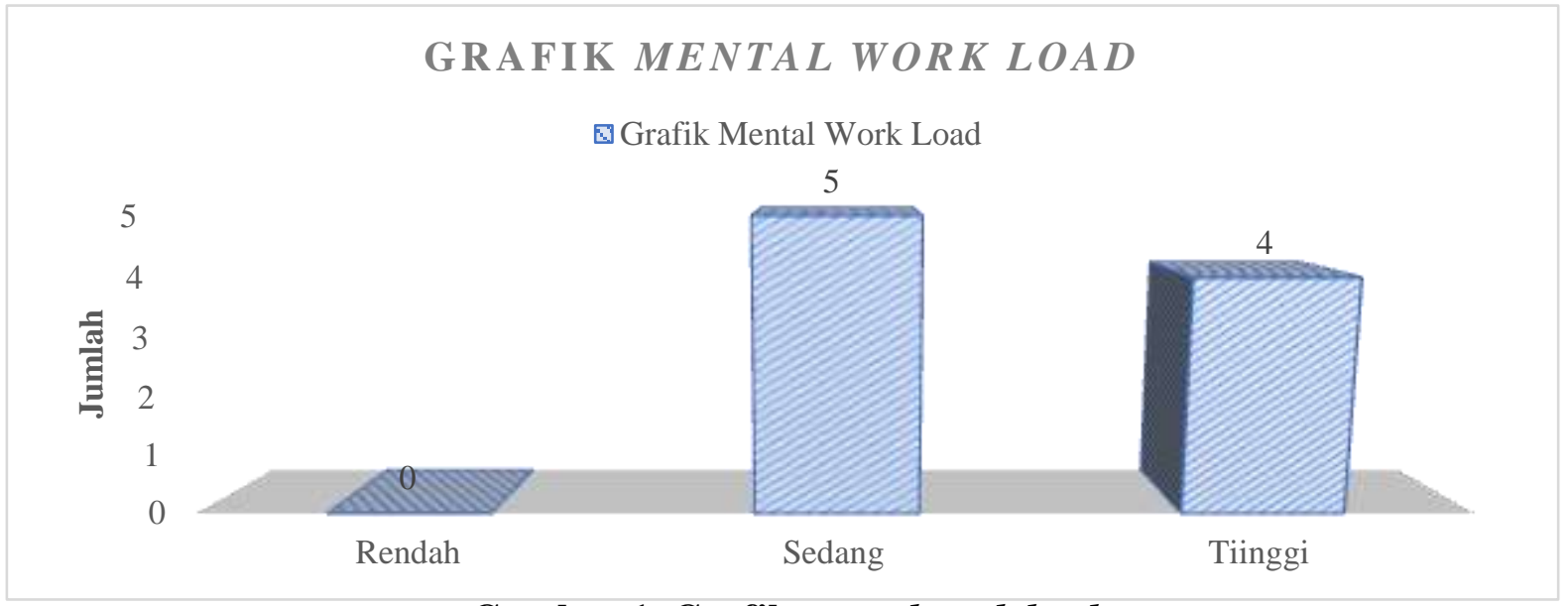

Gambar 1. Grafik mental work load 
Berdasarkan Gambar 1. merupakan nilai WWL yang didapatkan, maka ditemukan 4 karyawan $(44,44 \%)$ mempunyai mental work load tinggi, 5 karyawan $(55,56 \%)$ mempunyai mental work load yang sedang, serta 0 karyawan yang mempunyai beban kerja mental rendah. Menunjukan bahwa mayoritas karyawan di departemen produksi mempunyai mental work load di tingkatan sedang. Karyawan mempunyai tingkat work load yang tinggi mayoritas ada diposisi operator welding serta stamping. Tugas welding adalah pekerja melakukan proses pengelasan untuk menyambungkan sesuatu baik itu produk ataupun yang lain. Tugas stamping adalah pekerja melakukan proses pencetakan menggunakan dies serta mesin press biasanya plate dengan dicetak, untuk mendapatkan produk yang diinginkan. Segala kegiatan tersebut memerlukan aspek mental untuk melaksanakan pekerjaanya seperti kecermatan saat mengamati serta memikirkan biar tidak mengalami kesalahan ketika proses pembuatan produksi.

\section{Perbandingan elemen NASA-TLX}

Sesuai dengan data pengolahan NASA-TLX yang didapatkan, maka dapat ditemukan aspek yang paling lebih banyak didominasi, yang ditunjukan pada Tabel 6. Sesuai dengan hasil penjumlahan serta persentase masing-masing aspek, bisa ditemukan mana aspek paling mempengaruhi tingginya beban kerja mental karyawan departemen produksi PT. Putra Kemuning yakni bagian performance sebesar 24,36\%, aspek physical demand sebesar $20,62 \%$, aspek frustation level sebesar 17,24\%, aspek mental demand sebesar 12,77\%, aspek effort sebesar 12,59\%, dan aspek temporal demand sebesar 12,41\%. Berikut merupakan bagian mental work load NASA-TLX method yang lebih banyak didominasi di departemen produksi PT. Putra Kemuning jika disampaikan ke dalam gambar grafik, terlihat di Gambar 2 .

Tabel 6. Kategori penilaian mental work load

\begin{tabular}{cccc}
\hline Variabel & Total Hasil & Rerata & \% \\
\hline MD & 1400 & 155,56 & 12,77 \\
PD & 2260 & 251,11 & 20,62 \\
TD & 1360 & 151,11 & 12,41 \\
P & 2670 & 296,67 & 24,36 \\
FL & 1890 & 210,00 & 17,24 \\
E & 1380 & 153,33 & 12,59 \\
\hline
\end{tabular}

\section{GRAFIK ASPEK METODE NASA-TLX}

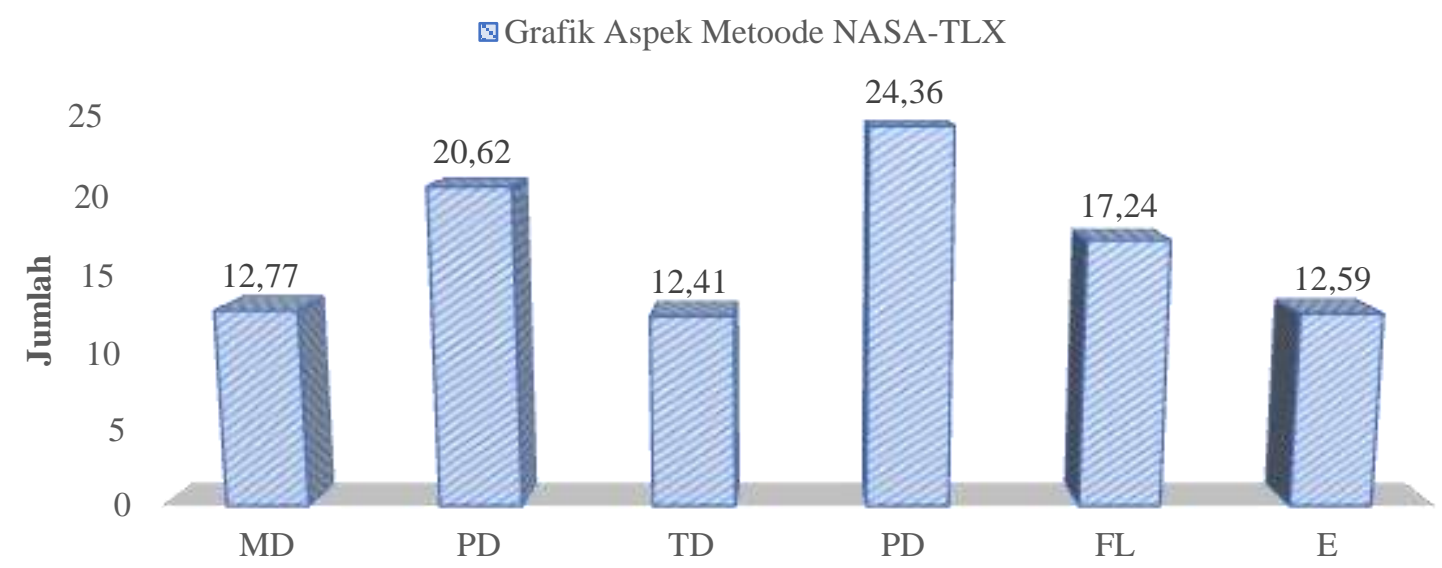

Gambar 2. Grafik aspek metode NASA-TLX 
Untuk menentukan berapa terbesar tingkatan kesuksesan yang diraih ketika mengakhiri kegiatan kerja yang sesuai dengan jenis pekerjaanya, hal ini merupakan aspek performance. Di PT. Putra Kemuning, pekerja diminta untuk dapat memenuhi permintaan produksi/harinya. Kemudian jika permintaan tinggi serta pekerja tidak dapat mengakhiri suatu pekerjaan sesuai dengan jam pekerjaan reguler, maka pekerja tersebut diwajibkan untuk tambah shift guna memenuhi permintaan produk. Dalam hal ini faktor paling mempengaruhi beban kerja mental yaitu aspek performance. Aspek physical demand serta aspek frustation level merupakan aspek lain yang memiliki persentase cukup tinggi. Untuk menentukan berapa besar kegiatan fisik yang diperlukan agar memenuhi performance yang diinginkan pekerja adalah aspek physical demand. Dalam menentukan berapa besar rasa ketidaknyamanan, menyerah, tersindir, terjadinya gangguan, disandingkan dengan rasa aman, senang dan nyaman, serta kebutuhan pribadi yang dapat dialami merupakan aspek frustation level.

\section{Usulan perbaikan}

Sesuai dengan hasil perhitungan skor akhir NASA- TLX diperoleh bahwa 4 operator mempunyai tingkatan mental work load tinggi, mental work load sedang diperoleh 5 operator, serta beban kerja mental ringan nol operator. Operator Welding dan Stamping adalah pekerja yang mempunyai mental work load mental tinggi. Variabel dominan yang berpengaruh pada hasil akhir mental work load sesuai dengan angket diberikan sebelumnya adalah faktor P-Performance, PD-Physical Demand, serta FL-Frustation Level. Hasil penelitian yang serupa memberikan usulan perbaikan yang dibagikan agar dapat menurunkan beban kerja mental adalah melalui dilakukannya penjumlahan pegawai dengan membagikan jumlah mental work load (Ramadhan, et al., 2014). Didapatkan rerata beban kerja pada hasil pembagian tersebut. Guna meminimalisir rerata mental work load pegawai merupakan tujuan dari penambahan pekerja. di departemen produksi PT. Putra Kemuning, perlu dilaksanakan penambahan jumlah pekerja mempunyai mental work load tinggi, yakni operator Welding serta Stamping. Penyelesaian sebagai berikut:

1. Total Work Load Operator Welding $=81,33$

Rerata Work Load Operator Welding

$($ Kondisi 1 pekerja $)=\frac{81,33}{1}=81,33$

Rerata Work Load Operator Welding

$($ Penambahan 1 pekerja $)=\frac{81,33}{2}=40,67$

$($ Penambahan 2 pekerja $)=\frac{81,33}{3}=27,11$

2. Total Work Load Operator Stamping $=79,33+88,67+90+90+77,33+81,33=506,66$

Rerata Work Load Operator Stamping

$($ Kondisi 6 pekerja $)=\frac{506,66}{6}=84,44$

Rerata Work Load Operator Stamping

$($ Penambahan 1 pekerja $)=\frac{506,66}{7}=72,38$

$($ Penambahan 2 pekerja $)=\frac{506,66}{8}=63,33$

Tabel 7. Rerata mental work load didasarkan usulan penjumlahan pegawai

\begin{tabular}{cccc}
\hline Pegawai & \multicolumn{3}{c}{ Rerata Mental Work Load } \\
& Keadaan Sebelumnya & Tambahan 1 Operatoor & Tambahan 2 Operator \\
\hline Operator Welding & 81,33 & 40,67 & 27,11 \\
Operator Stamping & 84,44 & 72,38 & 63,33 \\
\hline
\end{tabular}


Berdasarkan dengan perhitungan hasilnya mental work load di kondisi sebenarnya didapatkan jumlah nilai mental work load operator welding sebesar 81,33 serta rerata mental work load sebesar 81,33 (keadaan 1 operator). Jika dilaksanakan tambahan 1 operator, maka rerata mental work load operator welding membuat 40,67 (ringan) serta jika dilaksanakan tambahan 2 operator, maka rerata mental work load operator welding akan membuat 27,11 (ringan). Untuk operator stamping jumlah mental work load sebesar 506,66 serta rerata 84,44 (keadaan 6 operator). Jika dilaksanakan tambahan 1 operator, maka mental work load operator stamping membuat 72,38 (sedang), serta jika dilaksanakan tambahan 2 operator mental work load operator stamping membuat 63,33 (sedang). Dengan ini membuktikan bahwa adanya tambahan operator dapat mengurangi mental work load rerata pekerja terlebih operator Welding \& Stamping di departemen produksi PT. Putra Kemuning.

\section{SIMPULAN}

Kesimpulan dari penelitian yang telah dilakukan dan berdasarkan hasil pengolahan data dapat di simpulkan: Penyelesaian akhir yang diperoleh menggunakan metode NASA-TLX di departemen produksi PT. Putra Kemuning. Ditemukan 4 operator $(44,44 \%)$ mempunyai mental work load yang tinggi, 5 operator $(55,56 \%)$ mempunyai mental work load yang sedang, serta nol karyawan mempunyai mental work load rendah. Menunjukan bahwa mayoritas karyawan departemen produksi mempunyai mental work load di tingkat sedang. Pegawai yang mempunyai tingkat work load.yang tinggi mayoritas ada di posisi operator welding serta stamping. Aspek yang sangat berpengaruh dalam tingginya mental work load di departemen produksi PT. Putra Kemuning adalah aspek performance 24,36\%, aspek physical demand 20,62\%, aspek frustation level 17,24\%, aspek mental demand $12,77 \%$, aspek effort 12,59\%, dan aspek temporal demand 12,41\%. Agar dapat mengurangi tingginya mental work load di departemen produksi PT. Putra Kemuning adalah melakukan tambahan operator terlebih pada posisi operator Welding dan Stamping, yang mempunyai mental work load sangat tinggi. Tambahan karyawan dapat meminimalisir rerata mental work load karyawan tersebut.

\section{DAFTAR PUSTAKA}

Adiyanto, A. \& Herwanto, D., 2021. Tinjauan Kapasitas Persediaan Produk Fuji Seat PT. Tri Jaya Teknik Karawang. Jurnal Media Teknik dan Sistem Industri, V(1), pp. 33-40.

Afma, V. M., 2016. Analisa Beban Kerja Operator Inspeksi dengan Metode NASA-TLX (Task Load Index) di PT. XYZ. Journal of Profisiensi, IV(2), pp. 118-122.

Amri \& Herizal, 2017. Analisis Beban Kerja Psikologis dengan Menggunakan Metode NASA-TLX pada Operator Departemen Fiber Line di PT. Toba Pulp Lestari. Industrial Engineering Journal, VI(1), pp. 29-35.

Arsi, R. M., 2012. Analisa Beban Kerja untuk Menentukan Jumlah Optimal Karyawan dan Pemetaan Kompetensi Karyawan Berdasar pada Job Description. Surabaya : Jurnal Teknik ITS, I(1), pp. 1-10.

Bandono, A., Bastari, A. \& Suharyo, O. S., 2020. Effectiveness Naval Collaboration Flexible Learning (NCFL) Model in Increasing Learning Outcomes the Indonesia Naval Technology College. International Journal of Progressive Sciences and Technologies, XXIII(2), pp. 434-442. 
Bastari, A., Bandono, A. \& Suharyo, O. S., 2021. The Development Strategy of Smart Campus for Improving Excellent Navy Human Resources. Global Journal of Engineering and Technology Advances, VI(2), pp. 33-43.

Budiman, J., 2013. Analisa Beban Kerja Operator Air Traffic Control Bandara XYZ dengan Menggunakan Metode Nasa-TLX. 1st ed. Jakarta: CV. Media Pustaka.

Dewi, D. C., 2020. Analisis Beban Kerja Mental Operator Mesin Menggunakan Metode NASA TLX di PTJL. Journal of Industrial View, II(2), pp. 20-28.

Diniaty, D. D., 2016. Analisis Beban Kerja Fisik dan Mental Karyawan di Lantai Produksi pada PT. Pesona Laut Kuning. Jurnal Sains dan Teknologi Industri, XIII(2), pp. 203210.

Fithri, P. \& Anisa, W. F., 2017. Pengukuran Beban Kerja Psikologis dan Fisiologis Pekerja di Industri Tekstil. Jurnal Optimasi Sistem Industri, XVI(2), pp. 120-130.

Gautama, B. H., Fadhilah, I. D. \& Wibowo, A., 2020. Analysis of Implementation Work from Home on Employees Mental Workload in Customs and Excise Office of Tanjung Priok. Jurnal Perspektif Bea dan Cukai, IV(2), pp. 77-89.

Hart, S. G., 1988. Development of NASA Task Load Index (TLX). NASA-Ames Research. ed. California: Results of Empirical and Theoritical Research.

Kakerisa, A. L., Soleman, A. \& Prasetyo, B. R. A., 2019. Analisis Beban Mental Kerja dan Fisik Karyawan pada Lanati Produksi dengan Metode NASA-TLZ dan Cardio Vascular Load (Studi Kasus : PT. Fajar Utama Intermedia Cabang Ambon. ARIKA, XIII(1), pp. 63-74.

Kulak, F. A. \& Tuzuner, V. L., 2020. A Comparative Analysis of Flexible Working Patterns in Germany and Turkey. International Journal of Research in Business and Social Science, IX(4), pp. 1-11.

Muslimah, E. \& Hastuti, B. D., 2017. Evaluasi Beban Kerja Mental Masinis Kereta Api Prameks dengan Metode NASA-TLX (Studi Kasus: PT. KAI DAOP 6 Yogyakarta). Yogyakarta, Seminar dan Konferensi Nasional IDEC 2017.

Nugraha, B., 2021. Pengembangan Sumber Daya Manusia: Deskripsi Teoretis tentang Kinerja Pegawai, Penilaian Kinerja Pegawai dan Pemeliharaan SDM. Banyumas: CV. Pena Persada.

Putri, R. A., Tambunan, W. \& Fathimahhayati, L. D., 2018. Analisis Pengaruh Shift Kerja terhadap Beban Kerja Mental pada Operator Air Traffic Control (ATC) dengan Metode NASA-TLX (Studi Kasus: Bandara Udara Internasional X). Tekinfo: Jurnal Teknik Industri dan Informasi, VI(2), pp. 1-13.

Putri, U. L. \& Handayani, N. U., 2017. Analisis Beban Kerja Mental dengan Metode NASATLX pada Departemen Logistik PT. ABC. Industrial Engineering Online Journal, VI(2), pp. 1-10. 
Ramadhan, R., Tama, I. P. \& Yanuar, R., 2014. Analisa Beban Kerja dengan Menggunakan Work Sampling serta NASATLX untuk Menentukan Jumlah Operator. Jurnal Core.ac.uk, V(2), pp. 964-973.

Risma, A., 2010. Analisis Beban Kerja Mental dengan Metode NASA-Task Load Index. Jurnal Teknik Industri, I(1), pp. 1-10.

Rubio, S., Díaz, E., Martín, J. \& Puente, J. M., 2004. Evaluation of Subjective Mental Workload: A Comparison of SWAT, NASA TLX and Workload Profile Methods. International Journal of Applied Psychology, I(53), pp. 61-86.

Sari, S., 2019. Analisis Beban Kerja Menggunakan Metode Nasa - Task Load Index pada Karyawan Telkom Applied Science School Bandung. Jurnal Teknologi dan Manajemen Industri, V(2), pp. 1-6.

Suparti, E., Waruju, R. D. \& Laleat, S. G., 2018. Analisis Beban Kerja Mental Satpol PP Pariwisata Karanganyar. Jurnal Ilmiah Teknik Industri dan Informasi, VII(1), pp. 3846.

Utami, S. F., 2012. Analisis Beban Kerja Mental Guru Sekolah Dasar Menggunakan Metode NASA-TLX Studi Kasus di SDN Batu Tering. Jurnal Industri \& Teknologi, V(1), pp. 32-39.

Widananto, H. \& Nugraheni, D. D., 2019. Analisis Beban Kerja Mental plada Pekerja di Industri Pembuatan Tempe. Jurnal Ilmiah Teknik Industri dan Informasi, VII(2), pp. 87-94. 